\title{
Tooth Contact Analysis of Herringbone Rack Gears of an Impulse Continuously Variable Transmission
}

\author{
Gang $\mathrm{Li}^{1 *}$ and Zhi Geng ${ }^{2}$ \\ 0000-0003-2793-4615, 0000-0002-4513-9984 \\ ${ }^{1}$ Department of Mechanical Engineering, University of Maryland Baltimore County, Baltimore MD, 21250, United States \\ ${ }^{2}$ Shanghai Lanzai Information Technology Co., Ltd, Pudong, Shanghai, 200120, China
}

\begin{abstract}
Finite element based tooth contact analysis of a rack and pinion system of an impulse continuously variable transmission is performed in this study. The rack and pinion system are designed with involute profile herringbone tooth profiles. The involute profile herringbone tooth profile is a type of concave-convex profiles, which can be used for heavy load conditions. A contact load distribution model of the rack gear with involute profile herringbone tooth profiles is developed to analyze normal loads of any mashing position of the rack pinion system based on the minimum elastic potential energy theory. With the aim of improving the rack and pinion system design, the actual operation of gears under the terms of the three-dimensional tooth contact analysis is conducted. A rack gear with herringbone tooth profiles and a pinion are used to tooth contact analysis. Based on comparing the results of this analysis, a new type of rack gears with concave-convex involute tooth profile are advantages and disadvantages in terms of the contact stress.
\end{abstract}

Keywords: Rack gears; Tooth contact analysis; Finite element analysis; Herringbone tooth profile

\section{Research Article}

https://doi.org/10.30939/ijastech..837414

Received $\quad 08.12 .2020$

Revised 30.12.2020

Accepted 17.01.2021

* Corresponding author

Gang Li

gangli@umbc.edu

Address: Department of Mechanical Engineering, University of Maryland Baltimore County, Baltimore, MD, United States

Tel: +1 410-455-3309

Fax: +1 410-455-1052

\section{Introduction}

Rack gears are widely used in many areas, such as automobile, robotics, and renewable energy industry [1-3]. Impulse continuously variable transmissions (ICVTs) can provide reliable power conversion from a prime mover, such as an engine and an electric motor, to a driven part, such as a wheel and a chain, with a continuous output-to-input speed ratio $[4,5]$. Gears have various types according to their tooth profiles and tooth widths, and have a wide range of dimensions as small as the ones in small appliances to the very large gears used in heavy-duty applications $[6,7]$. Generally, gears are manufactured via hobbing [8] or forming cutting [9-11] based on the theory of gearing. For some gears with special tooth profiles, e.g., concave-convex and spiral tooth profiles, their manufacturing methods and machine-tools are complex. Since meshing performances of these gears with special tooth profiles are highly sensitive to manufacturing errors $[12,13]$, high manufacturing accuracy of gear machine-tools is required for these gears [1416].

Contact patterns and transmission errors are two typical methods for meshing performances evaluation of gear systems [17-19].
A tooth profile modeling method was developed to improve accuracy of tooth contact analysis for gear tooth profiles [20]. Some other meshing performances, e.g., power losses, can also be evaluated based tooth contact analysis $[21,22]$. Since these gears have convex-concave tooth profiles, they cannot be manufactured via standard gear manufacturing methods. During a manufacture in this way, for each of the gear modules and the radius of curvature, a different blade size and gear holder is needed. However, it's clear that these gears have many advantages, if they can be produced sufficiently in the industry [23,24]. Since these gears have better load-bearing capabilities, have a balancing feature for the axial forces, quiet operation feature and their lubrication characteristics is better than herringbone gears and spur gears. It's noteworthy that there are number of studies carried out recently in relation to these gears.

Rack gears are modeled with a computer-aided design (CAD) program in order to eliminate these problems, and in another study, it was emphasized that these gears can be manufactured in computer numerical control (CNC) milling machines using two different methods, and by making use of these presented methods, the manufacturing codes of the gears was created with CAD programs 
first time in the literature, and the manufacture of gears were carried out in an error-free manner using different materials. In this study, in order to determine the performance characteristics of these gears, manufactured correctly, for the applicability in the industry; three-dimensional (3D) tooth contact analysis of the gears have been carried out by using ANSYS.

The remaining part of this paper is organized as follows: a load distribution model of rack gears of the ICVT is introduced in Sec. 2. Some finite element analysis of the rack and pinion system are performed in Sec. 3. In order to verify operation performance of the rack and pinion system, some simulation results are discussed in Sec. 4. Finally, some conclusions from this study are presented in Sec. 5.

\section{Load Distribution Model of Rack Gears}

A 3D model of the rack gear for tooth contact analysis, as shown in Fig. 1, which are created by using CATIA. The rack gear is designed with a herringbone and curvilinear involute gear profile, as shown in Fig. 2.
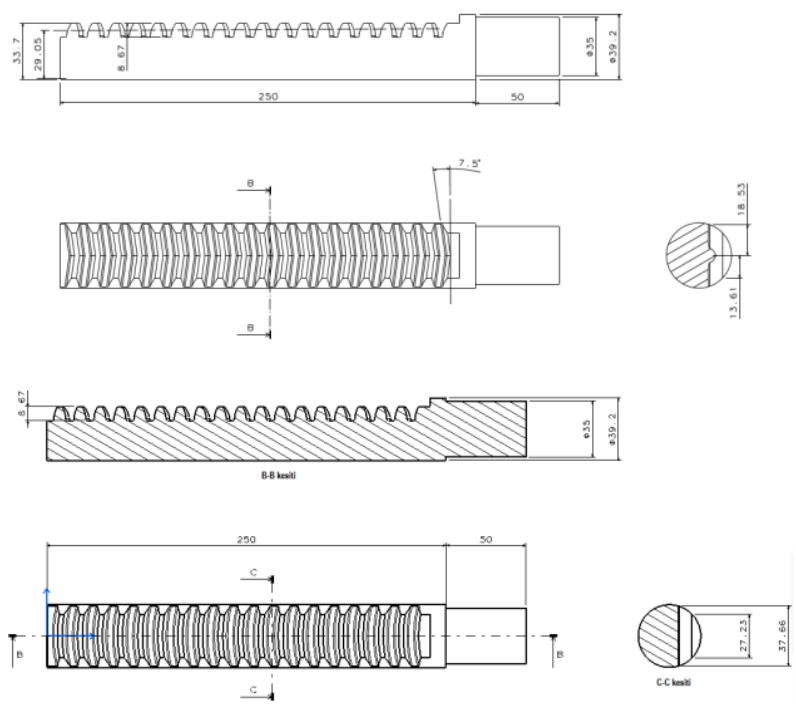

Fig. 1 Rack gear with the concave-convex involute profile

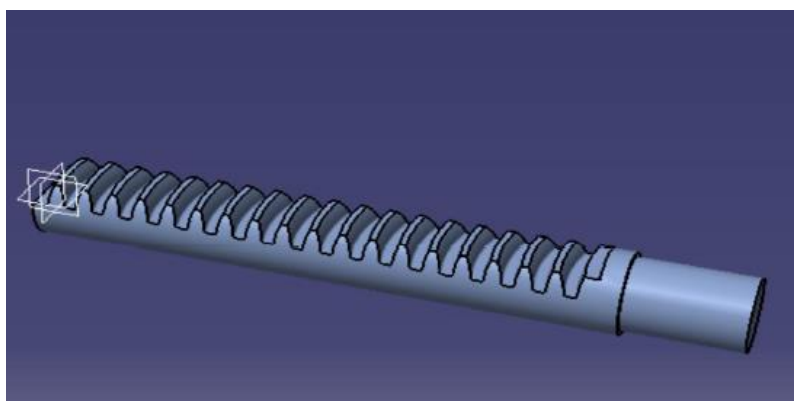

Fig. 2 3D model of the rack gear

A tooth model of an involute rack gear is used to describe its geometric parameters [25], as shown in Fig. 3. The base central angle $\gamma_{b}$ of a tooth can be represented as

$$
\gamma_{b}=\frac{\pi}{z}+\frac{4 \chi}{z} \tan \alpha_{n}+2\left(\tan \alpha_{t}-\alpha_{t}\right)
$$

where $z$ is the number of teeth, $\alpha_{t}$ and $\alpha_{n}$ are the transverse pressure angle and the normal pressure angle, respectively, and $\chi$ is the addendum coefficient. The pressure angle $\alpha_{c}$ at the contact point can be represented as

$$
\alpha_{c}=\frac{2 \pi}{z} \xi_{c}-\frac{\gamma_{b}}{2}
$$

where $\xi_{c}$ is the profile parameter of the contact point that can be represented as

$$
\xi_{c}=\frac{z}{2 \pi} \sqrt{\frac{r_{c}^{2}}{r_{b}^{2}}-1}
$$

in which $r_{b}$ is the base radius and $r_{c}$ is the profile radius of the contact point. The tooth central angle $\gamma(y)$ can be represented as

$$
\gamma(y)=\gamma_{b}-2 v(y)
$$

where $v(y)$ is the tooth profile angle.

A load distribution model of involute rack gears is used in this study based on the minimum elastic potential energy theory. The elastic potential energy of an involute rack gear tooth is composed of a bending component $U_{x}$, a compressive component $U_{n}$ and a shear component $U_{s}$ :

$$
U=U_{x}+U_{n}+U_{s}
$$

where $U_{x}, U_{n}$ and $U_{s}$ can be represented as

$$
\left\{\begin{array}{l}
U_{x}=6 \frac{F^{2} \cos ^{2} \alpha_{c}}{E B} \int_{y_{p}}^{y_{c}} \frac{\left(y_{c}-y\right)^{2}}{e^{3}(y)} \mathrm{d} y \\
U_{n}=6 \frac{F^{2} \sin ^{2} \alpha_{c}}{E B} \int_{y_{p}}^{y_{c}} \frac{1}{e(y)} \mathrm{d} y \\
U_{s}=\frac{C F^{2} \cos ^{2} \alpha_{c}}{2 G B} \int_{y_{p}}^{y_{c}} \frac{1}{e(y)} \mathrm{d} y
\end{array}\right.
$$

in which $F$ is the normal load, $F=10^{3} P / \omega r_{b}, P$ is the transmitted power, $\omega$ is the angular velocity of the pinion, $B$ is the tooth width, $E$ is the modulus of elasticity, $C$ is the shear potential correction factor, $G$ is the transverse modulus of elasticity, $y_{p}$ is the $y$ coordinate of the intersection of the root circle and the $y$ axis, $y_{c}$ is the $y$ coordinate of a contact point and

$$
e(y)=2 r(y) \sin \frac{\gamma(y)}{2}
$$

Suppose that there are $\hat{n}$ pairs of meshing teeth at a time instant; the normal load acting on the $\hat{i}$ th tooth surface can be represented as 


$$
F_{\hat{i}} \xi=\frac{\frac{1}{U_{\hat{i}}}}{\sum_{\hat{j}=1}^{\hat{n}} \frac{1}{U_{\hat{j}}}} F=\frac{V_{\hat{i}}}{\sum_{\hat{j}=1}^{\hat{n}} V_{\hat{j}}} F
$$

where $U_{\hat{i}}$ and $U_{\hat{j}}$ are elastic potential energies of the $\hat{i}$ th and $\hat{j}$ th meshing tooth surfaces, respectively, and $V_{\hat{i}}$ and $V_{\hat{j}}$ are inverses of elastic potential energies of the $\hat{i}$ th and $\hat{j}$ th meshing tooth surfaces, respectively. The elastic potential energy $U_{\hat{i}}$ of the $\hat{i}$ th meshing tooth surface can be represented as

$$
U_{\hat{i}}=\frac{l_{\hat{\imath}}}{\sum_{\hat{j}=1}^{\hat{n}} l_{c \hat{j}}} U
$$

where $l_{c \hat{i}}$ and $l_{c \hat{j}}$ are lengths of contact lines of the $\hat{i}$ th and $\hat{j}$ th meshing tooth surfaces, respectively. The involute rack gear tooth is divided into slices with unit lengths. The load acting on the $\hat{k}$ th slice can be represented as

$$
f_{\hat{k}} \xi=\frac{\varepsilon_{\beta} \cos \beta_{b}}{B} \frac{V_{\hat{k}} \xi}{\int_{l_{c i}} V_{\hat{k}} \xi \mathrm{d} l_{c i}} F_{\hat{i}} \xi
$$

where $\varepsilon_{\beta}$ is the face contact ratio, $\beta_{b}$ is the base spiral angle and $V_{\hat{k}}$ is the inverse of the elastic potential energy of the $\hat{k}$ th slice.

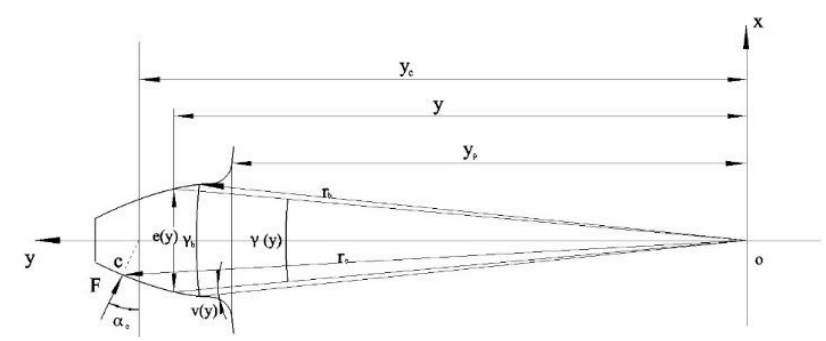

Fig. 3 Geometric parameters of an involute gear tooth

\section{Finite Element Analysis of Rack and Pinion System}

In this study, first the modeling of the gear was performed with CATIA, by using the analytical expressions that determine the gear profile. After the rack and spur gear pairs have been created, again using CATIA, the gears are mounted and the gear pairs have been created. Then the stress analyses of the gears have been carried out by ANSYS, after the gear pairs have been created with CATIA. When using ANSYS to perform stress analysis in gears by researchers, the gears have been assumed two-dimensional and the force has been applied to the nodes externally to perform the stress analysis [26, 27]. And in this analysis, a tooth profile of a threedimensional solid model was taken as the reference, and the maximum stress distribution and the clutch state of that maximum stress was determined for all gears during clutching, starting from the moment of first contact of a tooth to the last contact. The pinion gear rotates $13.173 \mathrm{deg}$, from the moment of first contact of a tooth to the last contact. This angle of rotation was divided into 6 equal pieces in order to better determine the maximum stress in this clutching period, and $8 \mathrm{Nm}$ load was applied to the pinion gear at each moment of rotation, under the flow limit, to observe the distribution of stresses produced on these three different gears, and the maximum Von Mises stresses and the maximum deformations were determined.

Table 1. Design parameters of the rack-pinion system

\begin{tabular}{c|c|c}
\hline Item & Pinion & Rack \\
\hline Number of teeth & 25 & 18 \\
\hline Module $(\mathrm{mm})$ & \multicolumn{2}{|c}{3} \\
\hline Center distance $(\mathrm{mm})$ & \multicolumn{2}{|c}{80} \\
\hline Face width $(\mathrm{mm})$ & 20 \\
\hline Pressure angle $(\mathrm{deg})$ & 30 \\
\hline Spiral angle $(\mathrm{deg})$ & 25 \\
\hline Material & $16 \mathrm{Ni3CrMoE}$ \\
\hline Hardness of the carburized layer & $\geq 800 \mathrm{HV}$ \\
\hline
\end{tabular}

Before starting finite element analysis, the strength values of the PEEK material used in the manufacturing of the gears were input to ANSYS, then model file created in CATIA was opened and the rack-pinion system was divided into finite elements with the help of the mesh menu of CATIA, as shown in Fig. 4. Since the tensions in regions other than the contact region are not important much, these areas were divided into finite elements automatically from the menu of the program. However, the finite element dimensions in the contact regions have been manually set to $0.55 \mathrm{~mm}$, for a fine grain mesh of the gear, since the stress in this area is important. The total number of elements of the finite element model of the rack-pinion system is 7,320,150. Some local segmentation of meshes of gear teeth are performed to improve finite element analysis accuracy and convergent to a stable condition.

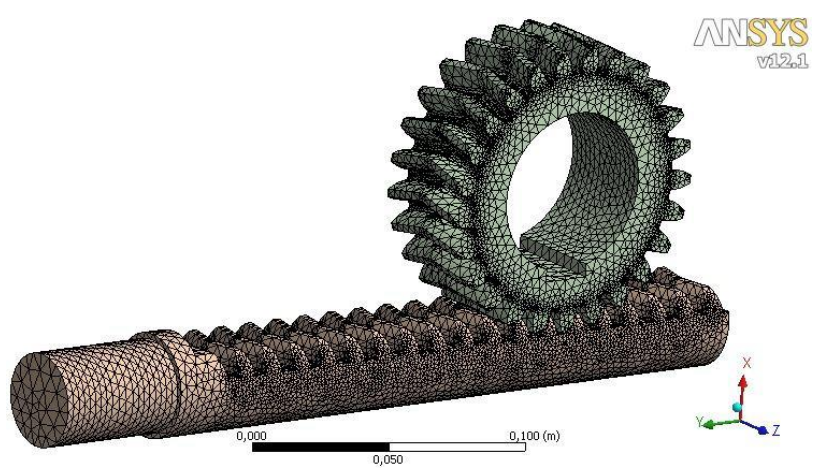

Fig. 4 Finite element model of the rack-pinion system

In order to apply load on to the pinion, the boundary conditions of the rack-pinion system were entered. In this step, which is prior to the final step, the almost realistic boundary condition values were applied to the finite element model of the rack-pinion system. The boundary conditions for the tooth model of the pinion are to locate the tooth force and the supports [7]. For this purpose, the rack gear was supported at one of its tips (Fig. 5, Fig. 6). The load 
on gear tooth surfaces has been applied in the form of torque on to the pinion, in accordance with the studies performed in the study. The contacting tooth surfaces have been defined in the rack-pinion system, and after defining that the rack and the pinion will undergo a linear elastic deformation, a static load applied to gear tooth surface of the rack-pinion system, as shown in Fig. 7. The maximum Von Mises stresses have been identified because of this tension.

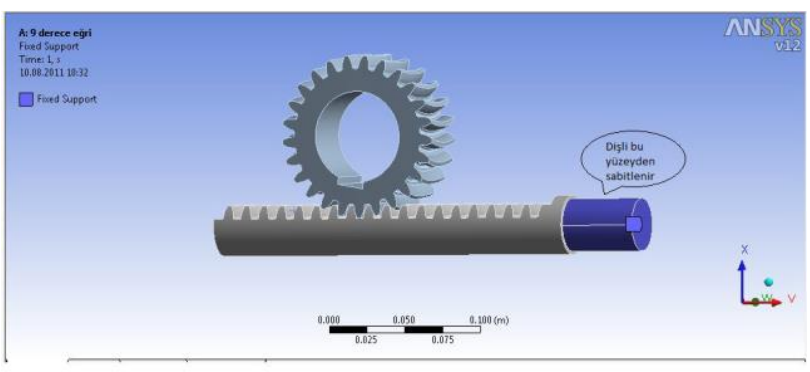

Fig. 5 Rack gear support boundary condition.

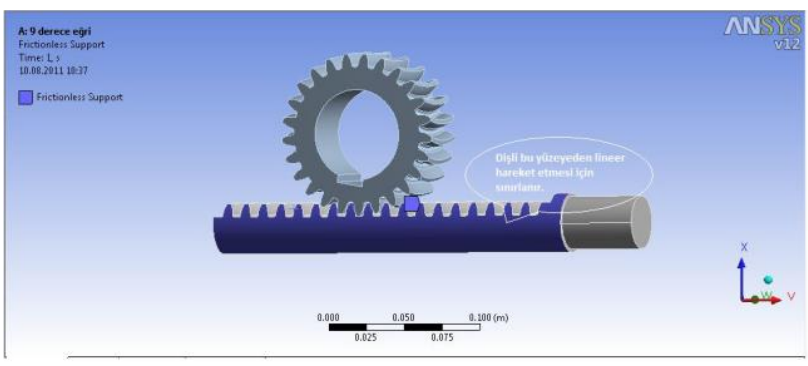

Fig. 6 Rack gear supporting boundary condition

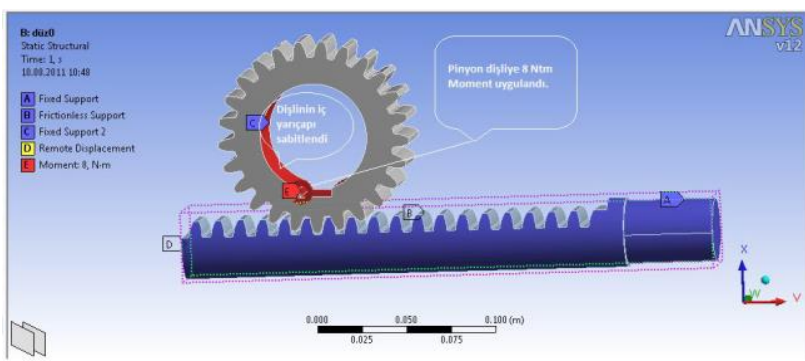

Fig. 7 Pinion gear supporting and load application

\section{Simulation Results and Discussion}

After achieving the necessary boundary conditions required for the analysis of the gears, the stress values for each angle of rotation were calculated. In the results of these stress analysis, carried out by the ANSYS, it has been observed that the weakest gear is the spur gear and the highest strength has been observed in herringbone gear, in the strength comparisons of the analyzed gear models. It has also been observed that the gear with concave-convex profile has stress values close to the herringbone gear.

Considering stress distribution, it has been observed that the stresses occurred on the concave-convex profile gears are smoother and the maximum stresses are at the center of the gear bow, as shown in Fig. 8. In the herringbone gear, however, the stresses are occurred at outer parts of the tooth profile in general, and as the clutch progresses the stresses shift to the center of the gear, as shown in Fig. 9. For spur gears, the maximum stresses were observed on a straight line along the bottom of gear teeth, as shown in Fig. 10.

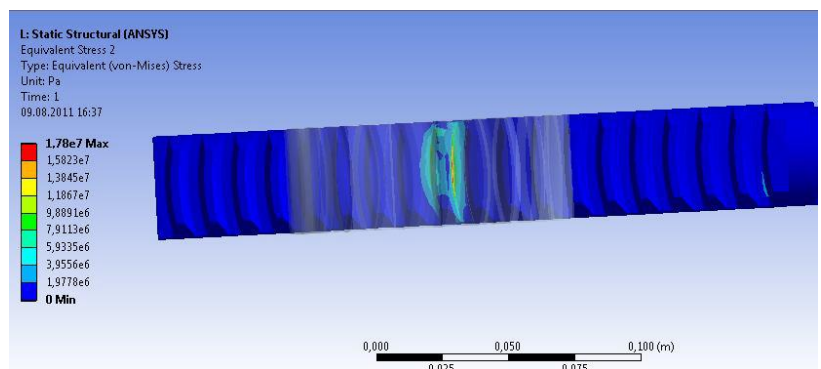

Fig. 8 Contact stress on a rack gear with a curvilinear tooth profile

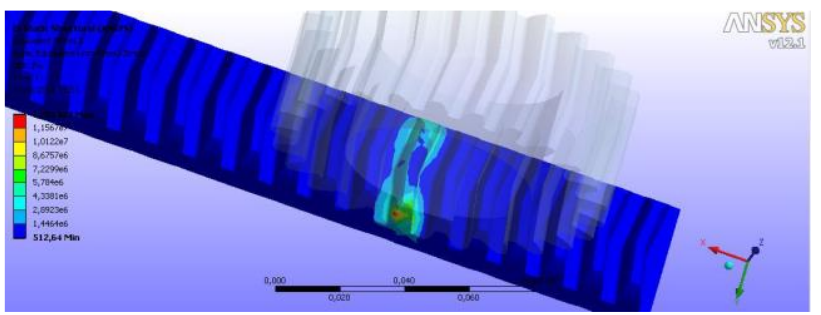

Fig. 9 Contact stress of a rack gear with a herringbone gear tooth profile

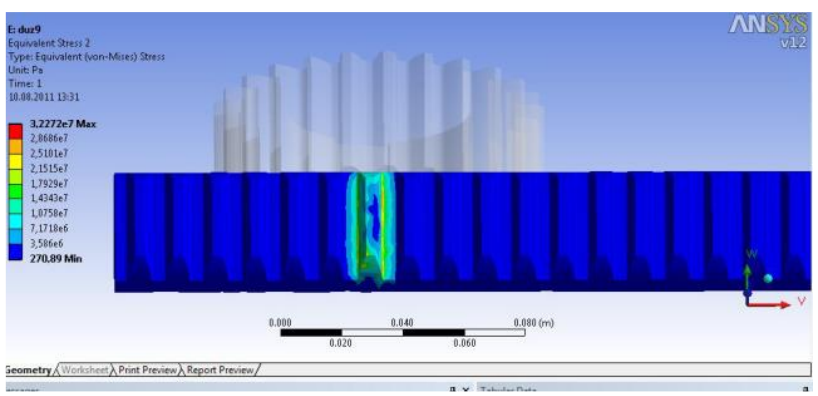

Fig. 10 Contact stress of a spur rack gear

\section{Conclusions}

In this study, a spur gear, a herringbone gear, and a concave-convex profile rack gear, having same module and number of teeth, were subjected to analysis. In the results of these stress analysis, carried out by using ANSYS, it has been observed that the weakest gear is the spur gear and the highest strength has been observed in herringbone gear, in the strength comparisons of the analyzed gear models. It has also been observed that the gear with concave-convex profile has stress values close to the herringbone gear, in terms of the strength. This will then shed light on the experimental studies to be performed on this type of gears.

Considering the stress distribution, it has been observed that the stresses occurred on the concave-convex profile gears are smoother and the maximum stresses are at the center of the gear bow. In the herringbone gear, however, the stresses are occurred at outer parts of 
the tooth profile in general, and as the clutch progresses the stresses shift to the center of the gear. And in spur gears, the maximum stresses were observed on a straight line along the bottom of gear teeth. Concave-convex gears will be more advantageous than the spur gears and herringbone gears, after finding the optimum radius through a research to be conducted on the curvature radii of the concave-convex gears. It's suggested that use of these gears will be more advantageous in places where load resistance is necessary and in the pumps with gears in particular. In order to ensure wider use of these gears in industry, other operating characteristics such as wear characteristics and operating temperatures should be determined.

\section{Acknowledgment}

The author is grateful for the financial support from the Maryland Energy Innovation Institute Energy Innovation Seed Grant.

\section{Conflict of Interest Statement}

The authors declare that there is no conflict of interest.

\section{CRediT Author Statement}

Gang Li: Conceptualization, Supervision, Writing-original draft, Writing-review\&editing, Validation, Zhi Geng: Data curation, Software

\section{Nomenclature}

$r_{b}$

: Base radius of the contact point $(\mathrm{mm})$

$r_{c}$

$z$

: Number of teeth

$\alpha_{c} \quad$ : Pressure angle at the contact point (deg)

$\alpha_{n} \quad$ : Normal pressure angle (deg)

$\alpha_{t} \quad:$ Transverse pressure angle (deg)

$\chi \quad:$ Addendum coefficient

$\xi_{c} \quad$ : Profile parameter of the contact point

$U \quad$ : Elastic potential energy

$F \quad$ : Normal load $(\mathrm{N})$

$P \quad$ : Transmitted power (W)

$\omega \quad$ : Angular velocity of the pinion (rpm)

$B \quad$ : Tooth width (mm)

E : Modulus of elasticity

\section{References}

[1] Srivastava N, Haque I. A review on belt and chain continuously variable transmissions (CVT): Dynamics and control. Mech Mach Theory. 2009;44(1):19-41.

[2] $\mathrm{Hu}$ YH, Li G, Zhu WD, Cui JK. An elastic transmission error compensation method for rotary vector speed reducers based on error sensitivity analysis. Appl Sci. 2020;10(2):481.

[3] Yan J, Li G, Liu K. Development trend of wind power technology. Int J Adv Eng Res Sci. 2020;7(6):124-132.

[4] Zhu Y, Liu KC. The present situation of research and development of impulse stepless speed variator. Pack Food Mach.
2003;21(5):11-14.

[5] Li G. Design and modeling of an impulse continuously variable transmission with a rotational swashplate. Int J Auto Sci Tech. 2020;4(4):307-313.

[6] Xu M, Zhang X, Hu G, Li G. The structure design and flow field simulation of a fire water monitor driven by worm gear with bevel gear. Mach Tool \& Hydra. 2016;6:57-61.

[7] Gu KL, Wang ZH, Li G, Liu XR. Optimization of geometric parameters of the straight conjugate internal gear pump based on GA. Elec Sci Tech, 2017;30(6):39-42.

[8] Zhang XL, Wang ZH, Li G. Research on virtual hobbing simulation and study of tooth surface accuracy of involute helical gears. Appl Mech Mater. 2012;155:601-605.

[9] Li G, Wang ZH, Zhu WD, Kubo A. A function-oriented active form-grinding method for cylindrical gears based on error sensitivity. Int J Adv Manuf Tech. 2017;92(5-8):3019-3031.

[10] Wang ZH, Zhu WM, Li G, Geng Z. Optimization of contact line for form-grinding modified helical gears based on neural network. China Mech Eng. 2014;25(12):1665-1671.

[11] Li G. An active forming grinding method for cylindrical involute gears based on a second-order transmission error model. SCIREA J Mech Eng. 2019;2(1):1-14.

[12] Li G, Zhu WD. An active ease-off topography modification approach for hypoid pinions based on a modified error sensitivity analysis method. ASME J Mech Des. 2019;141(9):093302.

[13] Li G, Wang ZH, Kubo A. Error-sensitivity analysis for hypoid gears using a real tooth surface contact model. Proc Instn Mech Eng, Part C: J Mech Eng Sci. 2017;231(3):507-521.

[14] Zhang WX, Wang ZH, Liu XR, Li G, Wan PL, Wang W. Research on optimization of temperature measuring point and thermal error prediction method of CNC machine tools. J Shaanxi University of Tech (Na Sci Ed). 2017; 33(3):18-24.

[15] Wang ZH, Cao H, Li G, Liu XR. Compensation of the radial error of measuring head based on forming grinding machine. J Mech Trans. 2017;41(3):143-146.

[16] Wang ZH, Song XM, He WM, Li G, Zhu WM, Geng Z. Tooth surface model construction and error evaluation for tooth-trace modification of helical gear by form grinding. China Mech Eng. 2015;26(21):2841-2847.

[17] Li G, Wang ZH, Kubo A. Tooth contact analysis of spiral bevel gears based on digital real tooth surfaces. Chin J Mech Eng. 2014;50(15):1-11.

[18] Wang ZH, Wang J, Ma PC, Li G. Dynamic transmission error analysis of spiral bevel gears with actual tooth surfaces. J Vib Shock. 2014;33(15):138-143.

[19] Wang ZH, Wang J, Wang QL, Li G. Transmission error of spiral bevel gear based on finite element method. J of Vib Shock. 2014;33(14):165-170.

[20] Li G, Wang ZH, Kubo A. The modeling approach of digital real tooth surfaces of hypoid gears based on non-geometric-feature segmentation and interpolation algorithm. Int J Prec Eng Manuf. 2016;17(3):281-292.

[21] Li G, Zhu WD. Design and power loss evaluation of a noncircular gear pair for an infinitely variable transmission. Mech Mach Theory. 2021;156:104137. 
[22] van Berkel K, Hofman T, Vroemen B, Steinbuch M. Optimal control of a mechanical hybrid powertrain. IEEE Trans Vehic Tech. 2012;61(2):485-497.

[23] Huang DQ, Wang ZH, Li G, Zhu WD. Conjugate approach for hypoid gears frictional loss comparison between different roughness patterns under mixed elastohydrodynamic lubrication regime. Tribo Int. 2019;140:105884.

[24] Li G, Wang ZH, Zhu WD. Prediction of surface wear of involute gears based on a modified fractal method. ASME $\mathrm{J}$ Tribo. 2019;141(3):031603.

[25] Li G, Wang ZH, Geng Z, Zhu WM. Modeling approach of digital real tooth surfaces of hypoid gears based on non-geometric-feature segmentation and interpolation algorithm. Chin J Mech Eng. 2015;51(7):77-84.

[26] Wang ZH, Yuan KK, Li G. Optimization identification for dynamic characteristics parameters of sliding joints based on response surface methodology. China Mech Eng. 2016;27(5):622-626.

[27] $\mathrm{Hu} \mathrm{YH,} \mathrm{Li} \mathrm{G,} \mathrm{Hu} \mathrm{AM.} \mathrm{Iterative} \mathrm{optimization} \mathrm{of} \mathrm{orbital} \mathrm{dynamics}$ based on model prediction. Front Arti Intel App. 2019;320:76-86. 